University of Wollongong

Research Online

Australian Institute for Innovative Materials -

Papers

Australian Institute for Innovative Materials

2005

Double injection as a technique to study charge carrier transport and recombination in bulk-heterojunction solar-cells

G Juska

Vilnius University

K Arlauskas

Vilnius University

G Sliauzys

Vilnius University

A Pivrikas

Attila Mozer

University of Wollongong, attila@uow.edu.au

See next page for additional authors

Follow this and additional works at: https://ro.uow.edu.au/aiimpapers

Part of the Engineering Commons, and the Physical Sciences and Mathematics Commons

Research Online is the open access institutional repository for the University of Wollongong. For further information contact the UOW Library: research-pubs@uow.edu.au 


\title{
Double injection as a technique to study charge carrier transport and recombination in bulk-heterojunction solar-cells
}

\begin{abstract}
Ambipolar charge carriermobility and recombination in bulk-heterojunction solar cells based on the mixture of regioregular poly(3-hexylthiophene) and 1-(3-methoxycarbonyl)propyl-1-phenyl-[6,6]-

methanofullerene (PCBM) has been studied using injection current transients. The experimental results demonstrate double injection with bimolecular recombination limiting the injection current. We found that charge carrier bimolecular recombination is significantly reduced compared to Langevin recombination. We have measured the temperature and electric field dependence of the reduced bimolecular recombination coefficient and the results suggest that the electron and hole pathways are different and the recombination is controlled by the probability of the carriers to meet at the polymer/PCBM interface.
\end{abstract}

\section{Keywords}

carrier, study, technique, double, bulk, recombination, cells, solar, charge, injection, heterojunction, transport

Disciplines

Engineering | Physical Sciences and Mathematics

\section{Publication Details}

Juska, G., Arlauskas, K., Sliauzys, G., Pivrikas, A., Mozer, A. J., Sariciftci, N. S., Scharber, M. \& Osterbacka, R. (2005). Double injection as a technique to study charge carrier transport and recombination in bulkheterojunction solar-cells. Applied Physics Letters, 87 (222110), 1-3.

\section{Authors}

G Juska, K Arlauskas, G Sliauzys, A Pivrikas, Attila Mozer, Serdar Sariciftci, Markus Scharber, and R Osterbacka 


\title{
Double injection as a technique to study charge carrier transport and recombination in bulk-heterojunction solar cells
}

\author{
G. Juška, K. Arlauskas, and G. Sliaužys \\ Department of Solid State Electronics, Vilnius University, Saulètekio 9 III K, 01513 Vilnius, Lithuania \\ A. Pivrikas ${ }^{\text {a) }}$ \\ Department of Physics, Åbo Akademi University, Porthansgatan 3, 20500 Turku, Finland and Graduate \\ School of Materials Research, Universities of Turku, Turku, Finland
}

A. J. Mozer and N. S. Sariciftci

Linz Institute for Organic Solar Cells, Johannes Kepler University, Linz, Austria

M. Scharber

Konarka Austria, Altenbergerstr. 69, A-4040 Linz, Austria

R. Österbacka

Department of Physics, Åbo Akademi University, Porthansgatan 3, 20500 Turku, Finland

(Received 17 June 2005; accepted 4 October 2005; published online 22 November 2005)

\begin{abstract}
Ambipolar charge carrier mobility and recombination in bulk-heterojunction solar cells based on the mixture of regioregular poly(3-hexylthiophene) and 1-(3-methoxycarbonyl)propyl-1phenyl-[6,6]-methanofullerene (PCBM) has been studied using injection current transients. The experimental results demonstrate double injection with bimolecular recombination limiting the injection current. We found that charge carrier bimolecular recombination is significantly reduced compared to Langevin recombination. We have measured the temperature and electric field dependence of the reduced bimolecular recombination coefficient and the results suggest that the electron and hole pathways are different and the recombination is controlled by the probability of the carriers to meet at the polymer/PCBM interface. (C) 2005 American Institute of Physics.
\end{abstract}

[DOI: $10.1063 / 1.2137454]$

The charge carrier mobility in organic solar cells is lower compared to crystalline semiconductors. Thus, to achieve the same power-conversion efficiency it is necessary to photogenerate a higher density of charge carriers. An increased carrier density causes a reduced lifetime due to bimolecular recombination and the efficiency might be reduced. Usually, the charge carrier lifetime is estimated from photocurrent transients after the excitation by a short light pulse. However, in organic materials this method is inaccurate, because the photocurrent transients depend not only on the decay of charge carrier concentration but also on the mobility relaxation within the broad density of states. ${ }^{1}$ To estimate lifetimes from transient absorption techniques is difficult because of the very large dispersion observed leading to power law decays. ${ }^{2}$

Double injection (DoI) current is a well known phenomena in inorganic materials, ${ }^{3-12}$ and it is a well known fact that recombination limits the DoI current. ${ }^{3}$ For achieving high efficiency organic electroluminescence DoI is important. ${ }^{13}$ Double injection has therefore also been studied in a variety of organic light emitting diodes, ${ }^{14-17}$ where both electrons and holes are injected and transported to the recombination zone at the interfacial layer. For efficient light emission DoI currents with efficient charge carrier recombination (e.g., Langevin-type) is required. ${ }^{4-17}$ For solar cells, however, photogenerated charge carriers has to be efficiently transported to the contacts without any type of carrier recombination. In this letter we demonstrate the presence of DoI current limited by a reduced (compared to Langevin-type)

${ }^{a)}$ Electronic mail: apivrika@abo.fi bimolecular recombination in bulk-heterojunction solar cells (BHSC). An analytical way to directly and independently estimate the ambipolar carrier mobility and bimolecular recombination coefficient as a function of electric field in highly efficient BHSCs is shown. This brings up new possibilities to evaluate the suitability of new materials for usage in organic solar cells.

The experimental setup is very simple utilizing a pulsed voltage source and an oscilloscope. The sandwich type samples were made by depositing a $1.9-\mu \mathrm{m}$-thick film from a blend of regioregular poly(3-hexylthiophene) and 1-(3methoxycarbonyl)propyl-1-phenyl-[6,6]-methanofullerene (PCBM) in the ratio 1:2 on top of a indium tin oxide glass substrates. ${ }^{18}$ As the top electrode a $1 \mathrm{~nm}$ lithium fluoride film followed by a $100 \mathrm{~nm}$ aluminum film was evaporated. Dark DoI current transients were measured by applying a forward bias voltage pulse over the sample electrodes while the conductivity and faster carrier mobility was measured using the carrier extraction using a linearly increasing voltage technique (CELIV). ${ }^{19}$

In case of DoI current into a semiconductor limited by bimolecular carrier recombination, the current-voltage dependence can be expressed as ${ }^{3}$

$$
\begin{aligned}
j_{s} & =\frac{8 e}{9} \sqrt{\frac{\left(\mu_{n}+\mu_{p}\right) \mu_{n} \mu_{p}\left(n_{0}-p_{0}\right)}{\beta}} \frac{U^{3 / 2}}{d^{2}} \\
& =\frac{8}{9} \frac{U}{d} \epsilon \epsilon_{0} \sqrt{\frac{\beta_{L}}{\beta \tau_{\sigma} t_{a}}},
\end{aligned}
$$

where $e$ is the electron charge, $\mu_{n}$ is the electron mobility, $\mu_{p}$ is the hole mobility, $n_{0}\left(p_{0}\right)$ is the electron (hole) concentra- 


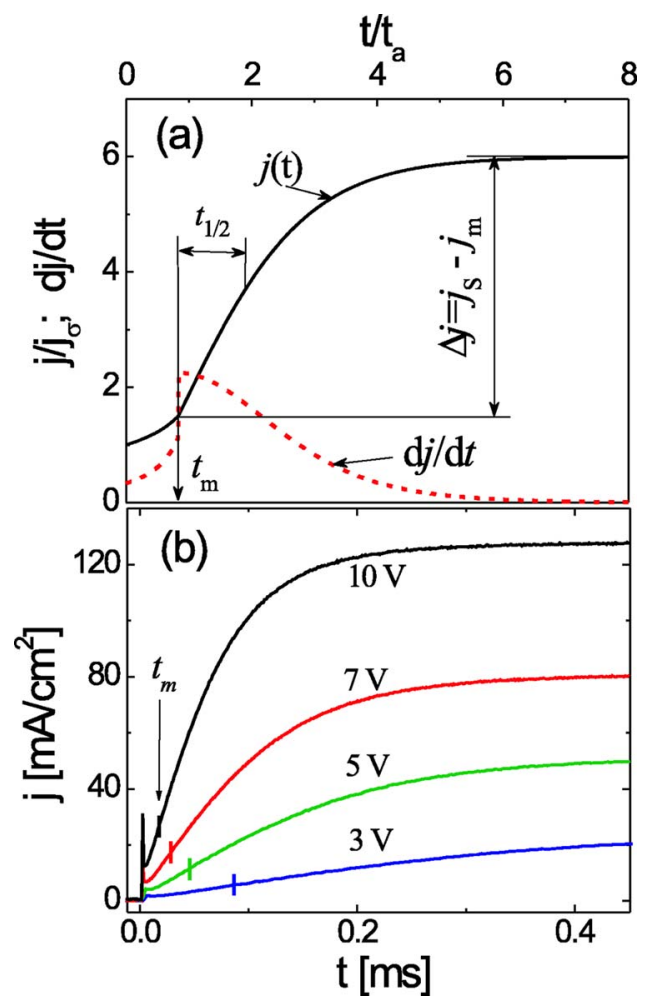

FIG. 1. (Color online) A schematic DoI current transient (solid line) calculated by using Eq. (2) with it's time derivative (dashed curve). (b) Experimentally measured DoI current transients in the BHSC for different applied square-voltage pulses. The maximum derivative $t_{m}$ is shown in each curve.

tion, $\beta$ is the bimolecular recombination coefficient, $U$ is the applied external voltage, $d$ is the sample thickness, $\epsilon\left(\epsilon_{0}\right)$ is the relative (absolute) dielectric permittivity, $\tau_{\sigma}$ is the dielectric relaxation time, $t_{a}$ is the ambipolar transit time, and $\beta_{L}$ $=e\left(\mu_{n}+\mu_{p}\right) / \epsilon \epsilon_{0}$ the Langevin recombination coefficient. Following the procedure outlined by Dean, ${ }^{6}$ DoI current transients into a semiconductor $\left(\tau_{\sigma}<t_{\text {tr }}\right)$ including bimolecular carrier recombination can be written as

$$
=\left\{\begin{array}{ll}
\sigma E\left(1-\frac{2}{3} \frac{t}{t_{a}}\right)^{-1 / 2}, & t<\frac{5}{6} t_{a} \\
\frac{3}{2} \sigma E+\left(j_{s}-\frac{3}{2} \sigma E\right) \tanh \left[\beta \Delta n_{s}\left(t-\frac{5}{6} t_{a}\right)\right], & t>\frac{5}{6} t_{a}
\end{array},\right.
$$

where $\sigma$ is the sample conductivity, $E$ the applied external electric field, and $\Delta n_{s}$ the saturated concentration of injected charge carriers. The ambipolar carrier mobility and transit time are related as ${ }^{6} \mu_{a}=d^{2} / t_{a} U=5 d^{2} / 6 t_{m} U$, where $t_{m}$ $=5 / 6 t_{a}$ is the maximum position of the current derivative and $\mu_{a}$ the ambipolar mobility (see Fig. 1).

To get an analytical equation for the bimolecular recombination coefficient we solve Eq. (2) when the DoI current is half of $\Delta j$ as shown in Fig. 1(a):

$$
t_{1 / 2}=\frac{\ln 3}{2} \frac{1}{\Delta n_{s} \beta}
$$

which can be rewritten as:

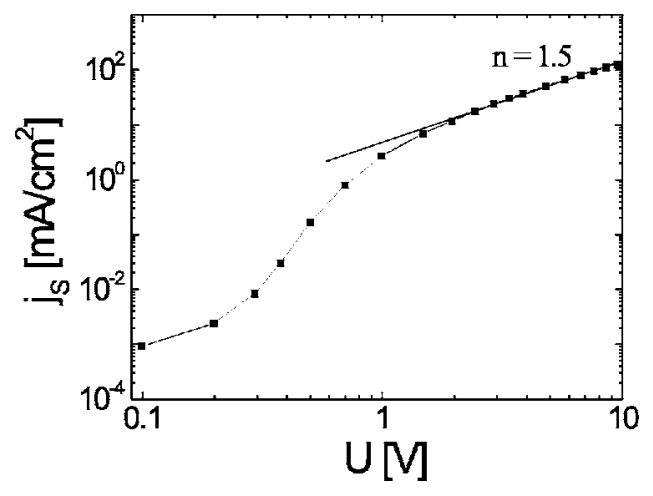

FIG. 2. Saturated current-voltage dependence of the BHSC showing the presence of double injection current as $j \propto U^{n}$ with $n=3 / 2$ above $\sim 1 \mathrm{~V}$.

$$
\beta / \beta_{L}=\frac{\ln 3}{2} \frac{\epsilon \epsilon_{0} U}{d} \frac{1}{t_{1 / 2} \Delta j} .
$$

When $j(0) \ll j_{s}$ another equation to calculate $\beta / \beta_{L}$ can be derived as

$$
\beta / \beta_{L}=0.45 \frac{\tau_{\sigma} t_{m}}{t_{1 / 2}^{2}}
$$

We have measured current-voltage characteristics for the BHSC shown in Fig. 2 and we found that $j \propto U^{1.5}$ above $U$ $=1 \mathrm{~V}$ suggesting that the DoI current into a high conductivity semiconductor is limited by bimolecular recombination, ${ }^{3}$ whereas at lower voltage the current is limited by the contacts. In Fig. 1(a) calculated DoI transients limited by bimolecular recombination and its derivative are shown together with measured transients at various applied external voltages in Fig. 1(b). After the ambipolar carrier transit time $t_{a}$, clearly seen as a peak in the time derivative of the current, the current grows until it reaches the saturation value $j_{s}$. The higher the external electric field the faster the current reaches its saturated value.

From the experimental transients we calculated $\mu_{a}$ and $\beta / \beta_{L}$ as shown in Fig. 3. The $\beta$ was independently measured using CELIV. ${ }^{20}$

The experimentally estimated $\beta / \beta_{L}$ in this sample demonstrates, that bimolecular recombination is reduced compared to Langevin recombination and is in good agreement with previous measurements. ${ }^{21}$ We also confirmed this result using the photo-CELIV method. ${ }^{20}$ The estimated value of

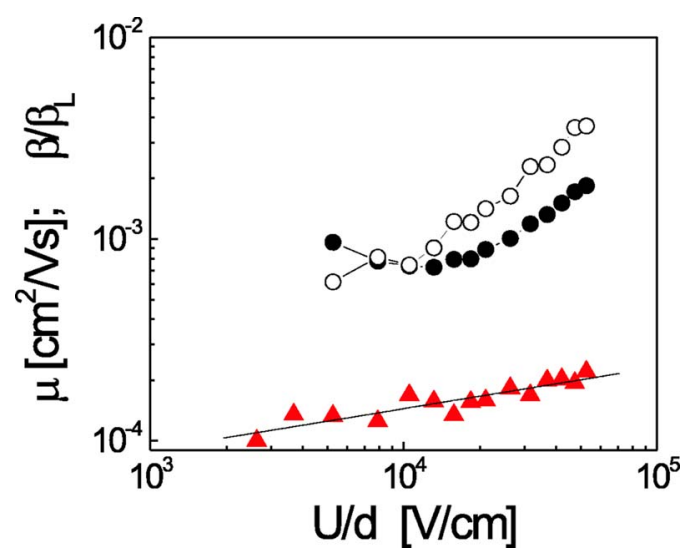

FIG. 3. (Color online) The estimated $\beta / \beta_{L}$ using Eq. (4) (filled circles) and Eg. (5) (open circles) together with $\mu_{a}$ (triangles) measured as a function of external electric field. 


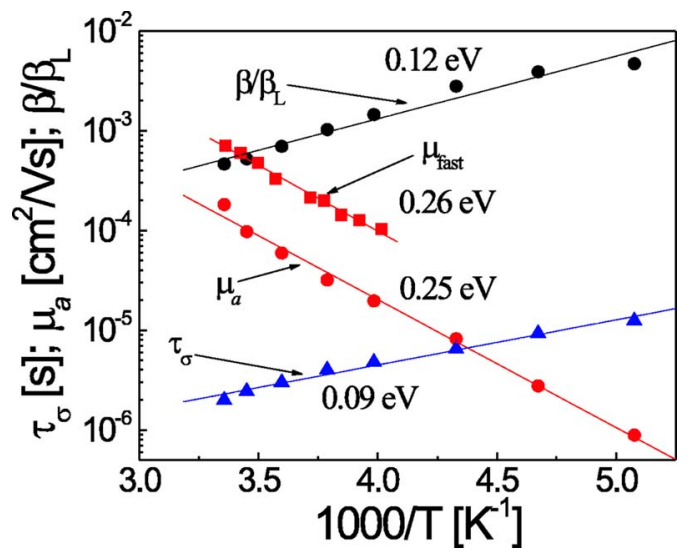

FIG. 4. (Color online) Dielectric relaxation time $\tau_{\sigma}, \mu_{a}$, and $\beta / \beta_{L}$ experimentally measured as a function of temperature. $\beta / \beta_{L}$ and $\mu_{a}$ are measured under an applied electric field of $U / d=2.5 \times 10^{4} \mathrm{~V} / \mathrm{cm}$.

reduced bimolecular recombination coefficient shows that the probability for an electron and hole to meet and recombine is greatly reduced and this suggests that electron and hole pathways are different.

We have also measured the temperature dependencies (Fig. 4) of $\mu_{a}$ and $\beta / \beta_{L}$ using DoI transients and $\mu_{\text {fast }}, \tau_{\sigma}$ using CELIV as shown in Fig. 4. We found that the activation energy for bimolecular recombination is smaller than for the Langevin recombination by $0.12 \mathrm{eV}$. According to Adriaenssens and Arkhipov when electrons and holes are moving through different pathways caused by the random potential a decrease of the bimolecular recombination as $\beta \propto \beta_{L} \exp ($ $-\Delta / k T)$, where $\Delta$ is the average height of the recombination barrier is expected. ${ }^{22}$ This predicts that the $\beta / \beta_{L}$ ratio must decrease with decreasing temperature. However, our measurements demonstrate the opposite dependence. The much higher activation energy of the electron and hole drift mobilities $\left(\Delta_{\mu}=0.25 \mathrm{eV}\right)$ compared to that of the conductivity $\left(\Delta_{\sigma}=0.09 \mathrm{eV}\right)$ in Fig. 4 suggests that trap-free hopping mobility $\left(\Delta_{\mu} \cong \Delta_{\sigma}\right)$ can be the reason for the activation energy of the Langevin recombination. However, even in this case the barrier $\Delta$ should be higher than $0.2 \mathrm{eV}$ to explain the observed $\beta / \beta_{L}=5 \times 10^{-4}$ at $T=300 \mathrm{~K}$, inconsistent with our data. Thus, we think, that the bimolecular recombination is partly caused by tunneling through the polymer-PCBM interface.
In conclusion we have measured DoI current transients in BHSCs and found that current transients are limited by bimolecular recombination. We show that DoI current transients can be used to independently estimate the ambipolar mobility and recombination coefficient. We measured the ambipolar mobility and bimolecular recombination coefficient as a function of applied external electric field and temperature. We found that the bimolecular recombination in BHSCs is reduced as compared to Langevin-type carrier recombination.

Financial support from the Academy of Finland through Project Nos. 203317 and 107684 is greatly acknowledged. A.J.M acknowledges the financial support from JSPS.

${ }^{1}$ H. Bässler, Phys. Status Solidi B 175, 15 (1993).

${ }^{2}$ I. Montanari, A. F. Nogueira, J. Nelson, J. R. Durrant, C. Winder, M. A. Loi, N. S. Sariciftci, and C. Brabec, Appl. Phys. Lett. 81, 3001 (2002).

${ }^{3}$ M. A. Lampert and P. Mark, Current Injection in Solids (Academic, New York, 1970; University Press, New York, 1999).

${ }^{4}$ R. Baron, O. J. Marsh, and J. W. Mayer, J. Appl. Phys. 37, 2614 (1966).

${ }^{5}$ R. H. Dean, Appl. Phys. Lett. 13, 164 (1968).

${ }^{6}$ R. H. Dean, J. Appl. Phys. 40, 585 (1969).

${ }^{7}$ W. D. Gill and I. P. Batra, J. Appl. Phys. 42, 2067 (1971).

${ }^{8}$ R. H. Dean, J. Appl. Phys. 40, 596 (1969).

${ }^{9}$ W. H. Weber, R. S. Elliott, and A. L. Cederquist, J. Appl. Phys. 42, 2497 (1971).

${ }^{10}$ R. Carius, F. Becker, R. Bruggemann, and H. Wagner, J. Non-Cryst. Solids 200, 246 (1996).

${ }^{11}$ R. Vanderhaghen and D. Han, J. Non-Cryst. Solids 190, 95 (1995).

${ }^{12}$ M. Hack and R. A. Street, J. Appl. Phys. 72, 2331 (1992).

${ }^{13}$ R. H. Friend, R. W. Gymer, A. B. Holmes, J. H. Burroughes, R. N. Marks, C. Taliani, D. D. C. Bradley, D. A. Dos Santos, J. L. Bredas, M. Logdlund, and W. R. Salaneck, Nature (London) 397, 121 (1999).

${ }^{14}$ W. Brütting, S. Berleb, G. Egerer, M. Schwoerer, R. Wehrmann, and A. Elschner, Synth. Met. 91, 325 (1997).

${ }^{15}$ Y. Kawabe, M. M. Morrell, G. E. Jabbour, S. E. Shaheen, B. Kippelen, and N. Peyghambarian, J. Appl. Phys. 84, 5306 (1998).

${ }^{16}$ D. J. Pinner, R. H. Friend, and N. Tessler, J. Appl. Phys. 86, 5116 (1999).

${ }^{17}$ V. R. Nikitenko, O. V. Salata, and H. Bässler, J. Appl. Phys. 92, 2359 (2002).

${ }^{18}$ F. Padinger, R. S. Rittberger, and N. S. Sariciftci, Adv. Funct. Mater. 13, 85 (2003).

${ }^{19}$ G. Juška, K. Arlauskas, M. Viliunas, and J. Kočka, Phys. Rev. Lett. 84, 4946 (2000).

${ }^{20}$ G. Sliaužys, G. Juška, K. Arlauskas, A. Pivrikas, R. Österbacka, M. Scharber, A. Mozer, and N. S. Sariciftci, Thin Solid Films (submitted).

${ }^{21}$ A. Pivrikas, G. Juška, A. J. Mozer, M. Scharber, K. Arlauskas, N. S. Sariciftci, H. Stubb, and R. Österbacka, Phys. Rev. Lett. 94, 176806 (2005).

${ }^{22}$ G. J. Adriaenssens and V. I. Arkhipov, Solid State Commun. 103, 541 (1997). 